DOI: $10.2478 / \mathrm{v} 10141-010-0020-2$

\title{
Equality, Equity and Inclusion: Transgender Athletes' Participation in Competitive Sports - a New Era
}

\author{
Singh Bal Baljinder ${ }^{1}$, Singh Kanwaljeet ${ }^{2}$, \\ Kumar Sharma Narinder ${ }^{3}$
}

\author{
${ }^{1}$ Guru Nanak Dev University, Amritsar, Punjab ,India \\ ${ }^{2}$ Institute of Engineering \& Technology, Jalandhar, Punjab, India \\ ${ }^{3}$ Guru Nanak Dev University Amritsar, Punjab, India
}

\section{KEYWORDS}

ABSTRACT

This review manifests an attempt towards the conceptual study of gender identity issues in competitive sports, foregrounding the genesis of policy matters in relation to transgender athletes. The study explores the motif of inter-relational dynamics between participation in sports of transgender athletes and medico-legal information related to transgender athletes, as the inclusion of transgender athletes is one of the latest and prominent equality challenges across the globe. The International Olympic Committee (IOC) has taken up the issue with regard to participation of sex-reassigned transsexuals and it has resulted in a heated debate for which a changing notion of gender verification came out. The issue under consideration has multi-faceted dimensions of interpretations centering on a desire to 'deconstruct' the present structuration of acceptance of sex and gender terminology. The resultant aim is to create a world-view of equality, respect for the 'other', and competitive fairness. The latent attempt of the paper is to deconstruct the binary of inequality in the field of sports with a view to give vibrational impetus for attaining the ideals of equality in sports which constitutes the basis of "authentic living", to quote Jean Paul Sartre.

sports, transgender athletes, International Olympic Committee (IOC), cultural constructs of society

\section{Introduction}

Sport is a social site where gender is performed and sexuality is regulated. By promoting hegemonic masculinity, patriarchal sport systematically excludes women and actively encourages homophobia. And yet, despite the inhospitable sporting environment, many gay men, lesbians, and transgendered people continue to play significant roles as athletes and activists. In recent years, there has been a shift in thinking about how we understand our lives as lived in what has been called the 'postmodern condition'. Many of the previously dominant foundational theories of sociology, or 'grand narratives' as they are sometimes known, have been challenged on the grounds that they are too rigid, exclusionary, or simply no longer relevant in a rapidly changing and complex world (Lyotard 1989, pp. 425-429). Their legitimacy has also been called too 'deconstructed', on the basis that they benefit some people at the expense of others. 
Gender and sexuality are two such social categories that are based on a rigid binary relationship (i.e., masculine/feminine, heterosexual/homosexual) in which one of the pair is privileged, legitimized, and valued over the other: specifically, masculinity over femininity and heterosexuality over homosexuality. Gender and sexuality are actually much more complex social constructions. Moreover - and critically - they play an important role in processes of social regulation and control (Foucault 1980).

\section{Discussion \& analysis}

In the last 45 years, 'gender' has been understood as different from 'sex' by reference to a difference between the body, biology and being male or female ('sex'), as well as the social and cultural roles inscribed on bodies; masculinity and femininity ('gender'). But originally the categories 'male' and 'female' were understood as residing in one body, and sex was a sociological category rather than a biological one (Laquer 1990, pp. 178-179). The idea that there was a male and female 'sex' in one body was superceded by the concept of two 'sexes' based on bodily differences between the reproductive organs, which became the foundation of sex difference in the eighteenth century. The sex/gender distinction was developed in research on intersex people in the 1950s, which later gave rise to transsexual identities in the 1960s. Later, psychoanalyst Robert Stoller used the distinction between sex and gender to argue that the biological sex of a person may not necessarily determine their 'core gender identity', a feeling of being male or female (Stoller 1968). As Jay Prosser states, it is 'the difference between gender identity and sex that serves as the logic of trans-sexuality' (Prosser 1998). Thus the sex/gender distinction enabled transgender and transsexual as categories. Many feminist critics have raised the issue of differentiating female, feminine, feminist - the prominent feminists being Toril Moi, Susan Gubar etc. To add it, the postmodern critical tools, e.g. Deconstruction, Postmodernism, Poststructuralism, Queer Studies etc., have played a dominant role in causing a perceptional revolution in the world order.

\section{Verification of gender}

Gender has for many years been an issue that surfaces from time to time in women's events at athletic meets. Gender verification for the purpose of competition has undergone significant evolution since attempts were made to introduce measures aimed at ensuring fair competition amongst female athletes. The first mechanism (introduced for international competition in the mid sixties) involved rather crude and perhaps humiliating physical examinations. This method quickly gave way to the method of determining 'sex' chromatin through buccal smear examination. However, as there were too many uncertainties associated with this method, many experts in the field clamored for its discontinuance, resulting in it being abandoned first by the IAAF in 1991 and then by the IOC in Sydney in 2000. In a nutshell, a distinctive sort of controversy has always engulfed the issue verification gender thereby involving the metaphysics of doubt in the core perception of the issue.

\section{Gender and sport}

Sport is a social and cultural process in which social constructions of masculinity and femininity play a key role. Sport may also be called an archetype always present in the conscious/unconscious mind of an individual at a given point of time, as per Jungian thought. Sport is traditionally associated with masculinity maintaining the logocentric/ patriarchal world order. In many societies, it is considered inappropriate for women to engage in sports, and women who do may be perceived as masculine. Women and men tend to engage in different types of physical activity and their attitudes towards sport may be very different. The women-only events (rhythmic gymnastics and synchronized swimming) and men-only events (boxing, wrestling, and weightlifting) reflect persistent biases 
regarding athleticism in each gender; the reasons for the same can largely be ascribed to the sociocultural constructs in a given society.

Generally speaking, sports for females compete for the beauty of motion while sports of males compete for the power, speed, strength and danger, speaking metonymically and metaphorically. A social cost that often confronts athletes attempting to participate in a sport that is non-traditional for their sex is the questioning of their sexuality. Author Mariah Burton Nelson describes this situation in her book, Are We Winning Yet?: "Homophobia in sports serves as a way to control women, both gay and straight." Whether a woman is lesbian or straight, homophobia in sports and the society at large tends to discourage girls and women from pursuing traditionally "masculine" activities such as contact sports and team sports for fear of being labeled a homosexual. "Female athletes in traditionally masculine sports challenge the social dictates about proper behavior for females; therefore, the reasoning goes, there must be something wrong with them. Focusing on sexual orientation unfairly denies women opportunities in sports on the basis of personal preferences irrelevant to athletic abilities. The mirrored argument highlights a desire of the patriarchy to weave a complex web of power-relations even in the field of sports as the criteria-constitution is largely from the side of "cultural construction", to quote Foucault's term.

\section{Transsexuals in competitive sport}

Changing social views and laws affecting sexuality has meant an increasing number of cases of transgender/transsexual athletes in sport. A transgender/transsexual means a person who was born in one sex and now identifies with, and lives as, another sex, and includes a person who has undergone a sex reassignment procedure. The phenomenon is new in the realm of the sporting world, as this kind of new consciousness on the part of humanity is vibrant across the world. Such types of cases are astonishing and challenging the socio-cultural stereotypes, thereby causing a new chord in the symphony of constructs. Men generally have an inherent performance advantage over women due to their greater average height, muscle mass and power, as the result of correspondingly different exposures to androgens. Therefore, it is considered fair that in sports men and women compete in separate categories.

The question now emerging is whether reassigned transsexuals can compete in fairness with others of their new sex (Gooren 2004). The pertinent question is how far the previous effects of testosterone in male-to-female transsexuals (M-F) are reversible upon androgen deprivation so that $\mathrm{M}-\mathrm{F}$ have no advantage over women, and, vice versa, what the effects are of androgen exposure in female-to-male transsexuals $(\mathrm{F}-\mathrm{M})$ on variables relevant to competition in sports. The issues being voiced pertain to the thesis in question. An analysis and deliberation is the call in order to achieve greater democracy, transparency and fairness.

\section{Transgendered athletes create a 'New Frontier' of issues}

The most recent and controversial decision on gender by the IOC came on May 27, 2004 when the IOC Executive Committee decided to allow transsexuals to compete in the Olympics and opened the way for transsexual athletes to compete in the 2008 Beijing Olympics. Transsexuals, male-tofemale or female-to-male, must meet three requirements to compete: "Completion of surgical anatomical changes, including external genitalia changes and gonadectomy; legal recognition of assigned sex by the appropriate official authorities; and sufficiently long and verifiable administration of hormonal therapy appropriate for the assigned sex to minimize gender-related advantages in sport competitions. Eligibility should begin no sooner than two years after gonadectomy." The quoted guidelines have brought a revolutionary change with respect to perceiving the issue that carries almost opposite significations as per the 'way of the world'. However, it has opened up new frontiers of 
deliberation to bring about empirical and qualitative understanding pertaining to the issue under consideration.

\section{Conclusion}

The International Olympic Committee (IOC) has taken an inevitably arbitrary decision with regard to the participation of sex-reassigned transsexuals in elite sports (Gooren 2008, pp. 427-432): the IOC's transsexual policy as currently stated is deficient. More specifically, the IOC has not sufficiently demonstrated that transsexual athletes do not have competitive advantages over typically gendered athletes. It is the responsibility of the IOC to reduce the various doubts about transsexual athletics. It is clear, from the scientific, socio-cultural and ethical criticisms outlined in this paper, that sex testing (gender verification) was/is inappropriate. When it comes to Gender Testing, the policy of the IOC had to be rethought and was criticized because it involved only testing women to ascertain their gender. With a view to evolve a holistic understanding of the issue in question, an international debate of intellectuals belonging to various knowledge disciplines should be initiated.

\section{REFERENCES}

Foucault, M. (1980). The History of Sexuality: Volume I: An Introduction. New York: Vintage.

Stoller, R. J. (1968). Sex and Gender: On The Development of Masculinity and Femininity. New York: Science House.

Gooren, J. G. \& Bunck, C. M. (2004). Transsexuals and competitive sports. The Netherlands. European Journal of Endocrinology, 151, pp. 425-429.

Laqueur, T. (1990). Making Sex: Body and Gender from the Greeks to Freud. Cambridge, Mass.: Harvard University Press.

Louis, J. G. (2008). Hormone Doping: Detection and Deterrence Olympic sports and transsexuals. Asian Journal of Andrology, 10, pp. 427-432.

Lyotard, J. F. (1989). The Postmodern Condition: A Report on Knowledge (pp. 178-179). Minneapolis: University of Minnesota Press.

Prosser, J. (1998). Second Skins: The Bodily Narratives of Transsexuality. New York: Columbia University Press.

AUTHOR'S ADDRESS: Baljinder Singh Bal Department of Physical Education Guru Nanak Dev University

Amritsar, Punjab, India

Email: bal_baljindersingh@yahoo.co.in 